carnations in cell culture, Tremmel says. Another challenge will be getting permission to exhibit the work: although the blue carnations have been approved for sale in Japan, the de-engineered white carnations may need regulatory approval before they can be taken out of a laboratory.

In addition to its creative possibilities, CRISPR also poses potential for mischief. The US Federal Bureau of Investigation's Bioterrorism Protection Team has painstakingly forged relationships with the biohacker community over the past few years and regularly reminds its members to keep an eye out for suspicious activity. Those concerns may be unnecessary, says Todd Kuiken, who studies science policy at the Wilson Center, a think tank in Washington DC. Most biohackers have benign goals, he says, such as creating rainbow-coloured bacteria or brewing distinctive beer.

There is also a tendency to overestimate what a typical DIY biologist can do, Kuiken adds. Reagents such as enzymes and antibodies are expensive, molecularbiology experiments are time-consuming and equipment that professional scientists take for granted is often beyond the means of individuals or community labs. And most community labs insist that their members work only with organisms that require the lowest level of biosafety precautions, which leaves human cells and most pathogens off the menu. In some parts of Europe,

\section{ONATURE.COM} CRISPR: The good, the bad and the unknown nature.com/crispr genetic engineering is illegal outside of professional facilities. Given the constraints of a DIY lab, many hobbyists resort to CRISPR only when they need an extremely precise change to the genome, says Keoni Gandall, a 16-year-old biohacker and science-fair champion from Huntington Beach, California, who has been working with polymerase chain reaction machines and centrifuges at home for about three years. So far, Gandall has used CRISPR only while volunteering in a local university lab. "It's pretty good," he says.

One of the biggest fears surrounding CRISPR is that it could be used to create a genetic modification designed to spread through a population of organisms at an unnaturally fast rate. But Dan Wright, an environmental lawyer and DIY biohacker in Los Angeles, California, thinks that such a scenario is still beyond the ability of most amateurs. Constructing such a system would surpass the relatively simple tweaks that he and his colleagues are contemplating.

"It's too difficult," Wright says. "Just knocking out a gene in one plant is enough of a challenge for a biohacker space at this point." -

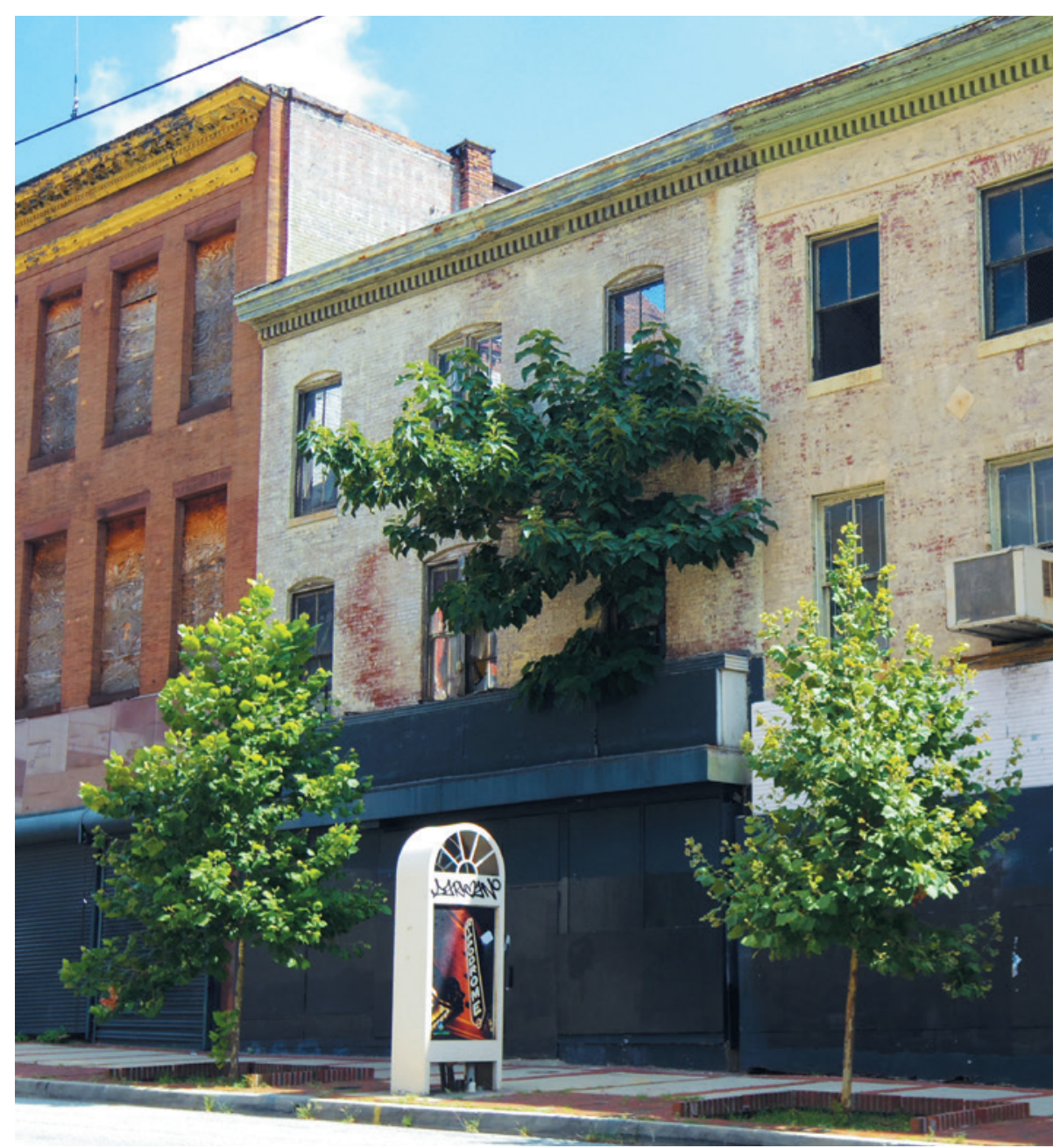

A tree grows in Baltimore: the city is at the heart of the burgeoning field of urban ecology.

ECOSYSTEMS

\title{
Ecologists embrace their urban side
}

\section{Climate change and the rise of cities have broadened what it means to study ecosystems.}

\section{BY DANIEL CRESSEY, BALTIMORE, MARYLAND}

A concrete megalith overshadowed by skyscrapers and surrounded by roads that roar with traffic, the convention centre in downtown Baltimore may seem an inappropriate setting for an ecology conference. But the resolutely urban backdrop for the annual meeting of the Ecological Society of America (ESA) is a fitting symbol of the growing acceptance of, and interest in, 'urban ecology' - the study of cities and the organisms that dwell in them as ecosystems.
"In the past 10 years, it's really become more mainstream. People's reactions have shifted from 'What's that?' or 'Why do you do that?' to 'Oh, cool,' says Laura Martin, a historian and urban ecologist at the Harvard University Center for the Environment in Cambridge, Massachusetts. She presented work at this year's centennial meeting (which ran on 9-14 August) showing that orange jewelweeds (Impatiens capensis) in Manhattan and other urban settings are evolving defences to incursions of certain deer that eat them (L. J. Martin et al. J. Ecol. 103, 243-249; 2015). Martin is part of a team that called at 
- the 2010 ESA meeting for more researchers to resist ecology's traditional bias towards pristine ecosystems (Nature http://doi.org/fwd62r; 2010).

This now seems to be happening. The sheer number of presented papers relating to cities this year points to a "phenomenal" growth of urban ecology, says Wayne Zipperer of the US Department of Agriculture Forest Service, who studies the urbanization of ecosystems in Gainesville, Florida. He recalls an ESA conference in the early 1990s that had just one oral presentation and one poster on the sub-field - this year, there were around 450 presentations, posters and events that touched on urban issues, roughly $10 \%$ of the conference total. Among them: a study of people in New York City, in particular immigrants from China, who rely on fungi and street trees such as ginkgo, white oak and linden for foods and medicines; and research showing that urban streams are as microbially diverse as wild ones.

The rise in papers shows "the maturity of urban ecology”, says Mark McDonnell, director of the Australian Research Centre for Urban Ecology in

Melbourne and editor of the new Journal of Urban Ecology, which started accepting submissions in March.

Urban ecologists attribute the swell of interest in their discipline to multiple factors, including the realization that human actions are warming the planet, that people are migrating to cities in increasing numbers and evidence that the study of urban ecosystems provides important and practical insights.

One move in particular that spurred the field was the decision in 1997 by the US National Science Foundation (NSF) to include two cities - Baltimore and Phoenix, Arizona -

\section{"Standing room only for urban ecology? When does that happen?"}

in a group of more than 20 long-term ecological research (LTER) sites that it funds. The studies based on these sites "changed the way ecologists feel about working in urban situations", says Steward Pickett, an urban ecologist at the Cary Institute of Ecosystem Studies in Millbrook, New York, and director of the Baltimore LTER site.

The studies are offering up results. Among many findings, the Baltimore Ecosystem Study showed that urban streams - historically considered useless dead zones - retain nitrogen run-off from fertilizers, providing a valuable 'ecosystem service' by preventing the nitrogen from reaching other water courses where it can spawn damaging algal blooms.
Such findings are becoming ever more important as both the absolute number of people and the proportion of the world's population living in cities grows, and as cities seek resilience to the effects of climate change, said sustainability scientist Nancy Grimm to meeting attendees. In July, researchers including Grimm - who heads the Phoenix LTER project from Arizona State University in Tempe - launched the Urban Resilience to Extremes Sustainability Research Network, a US $\$ 12$-million project funded by the NSF. The aim is to work out how cities can be designed to better withstand storms such as Hurricane Sandy, which hit New York in 2012, and Hurricane Katrina, which tore apart New Orleans in 2005. Such extreme weather events are predicted to become more frequent in future.

The behaviour of ecologists at the meeting suggests that they may already be converts. As one session started, Madhusudan Katti, an ecologist at California State University in Fresno, looked around as people continued to file into the overcrowded room. "Standing room only for urban ecology?" he said. "When does that happen?" Jon Christensen, a historian of science and the environment at the University of California, Los Angeles, detects another sign that a shift has occurred. "The city is no longer 'the other', the negative example contrasted with the pristine," he says. "Urban ecology has arrived." - 